\title{
PERFORMANCE: A MOBILIDADE POSTA EM CENA
}

Olga Valeska*

RESUMO: Neste artigo, analisaremos a obra Korso, do escritor português Luis Serguilha, que foi publicada pela editora brasileira Dulcinéia Catadora, em volumes impressos em papel reciclado e editados por filhos de catadores de papel. Para essa análise, usaremos o conceito de performance como operador de leitura.

PALAVRAS CHAVE: Poesia. Dança. Corpo. Performance.

A arte da performance teve seu momento inaugural nos anos 60, com 0 surgimento do trabalho fotográfico "Salto no Vazio" de Yves Klein. Nesse trabalho, o artista captura a imagem de seu próprio corpo suspenso num salto, que parte da janela de um prédio residencial para as ruas de Paris. Denunciando o direcionamento desumano dos recursos públicos na corrida espacial, o artista encena, em um ato de protesto, a entrega radical do corpo ao dizer da arte, explicitando a sua responsabilidade pessoal diante da sociedade de seu tempo. Nesse gesto, o fotógrafo registra um momento único de transposição das fronteiras entre o público e privado, em um trabalho que, significativamente, não foi exposto em galerias de arte, mas em panfletos distribuídos em praças e ruas.

Porém, se o registro desse trabalho fotográfico marcou um momento histórico para o surgimento da moderna performance artística, esse tipo de manifestação pública não tem uma origem tão clara nem tão recente:

[...] podemos localizar, segundo alguns autores, a verdadeira pré-história do gênero remontando aos rituais tribais, passando pelos mistérios medievais e chegando aos espetáculos organizados por Leonardo da Vinci do século XV, e Giovanni Bernini duzentos anos mais tarde. (GLUSBERG, 2009. p.12)

\footnotetext{
Centro Federal de Educação Tecnológica, Belo Horizonte, Brasil. Imeio: olgavaleska@dppg.cefemg.br
} 
É interessante observar que existem importantes estudos sobre práticas rituais promovidas no interior das sociedades em todas as épocas. ${ }^{1}$ Tais práticas configuram fórmulas de demarcação de comportamentos e relações sociais que poderiam ser chamadas de arquetípicas. Guardadas as diferenças culturais, pode-se dizer que os rituais, em sociedades tradicionais ou não, configuram protocolos gestuais onde se encenam práticas coletivas consolidadas como "programas":

Sob esse ponto de vista, a performance desenvolve verdadeiros programas criativos, individuais e coletivos. Como objetos culturais, os programas gestuais exigem sua definição genética. O programa conduz a seu próprio resultado, como um algoritmo de engendramento. (GLUSBERG, 2009, p.53)

Porém, o movimento de (auto)engendramento mencionado acima, ao explicitar seu próprio código gerador, seu modus operandis, acaba por denunciar a dimensão convencional do "comportamento" social do homem porque deixa ver sua constituição como espaço semiótico: "A cultura nos leva a tomar como naturais as sequências de ações e comportamentos a que estamos habituados, porém a semiótica vai questionar as condições de geração dessas ações e os fatores determinantes das mesmas". (GLUSBERG, 2009, p.53)

De qualquer maneira, toda manifestação artística resulta da inevitável dinâmica das transformações no campo das relações sociais e culturais, juntamente com a criatividade pessoal de seus atores. Além disso, a performance como manifestação pública do corpo dado em espetáculo revela o caráter exterior dos códigos compartilhados na intimidade de cada corpo individualmente, ativando uma dimensão que abala as fronteiras entre o público e o privado.

Herdeiras das vanguardas européias, as intervenções performáticas na atualidade, muitas vezes também forçam os limites do espaço reservado ao espetáculo artístico. Elas invadem a cena urbana e obrigam os habitantes das

\footnotetext{
${ }^{1}$ Conferir os importantes estudos desenvolvidos por Mircea Eliade, Joseph Campbell, Heinrich Zimmer, entre outros.
} 
cidades a tornarem-se espectadores/atores, transpondo, assim, os limites entre o mundo da representação e o cotidiano.

\begin{abstract}
Nas performances não há um elemento indicativo do que seja pertinente, como jogos de luzes com focalizações cênicas. Interessa, isso sim, uma observação do interno frente ao externo, do pequeno frente ao monumental, do velado frente ao desvelado. (GLUSBERG, 2009, p.56).
\end{abstract}

Assim, a performance, como linguagem, proporciona uma tensão entre as fronteiras que constituem a cena urbana, relativizando os limites estabelecidos entre a atuação do corpo no espaço coletivo da realidade cotidiana e a ação poética no espaço cenográfico propriamente dito.

Em outro aspecto, a performance, na atualidade, tende a valorizar o momento da criação, focalizando o trabalho artístico não mais na obra acabada, mas no artista e em seu processo criativo. A ação performática sustenta-se, assim, em uma linguagem entre sensível e conceitual. Uma linguagem que chama à cena pública o corpo do artista e o corpo do espectador no momento mesmo da criação: "[...] o corpo humano é a mais plástica e dúctil das matérias significantes, a expressão biológica de uma ação cultural” (GLUSBERG, 2009, p.52).

Como arte experimental, cada performance jamais poderá se repetir. Cada espetáculo se desenvolve em uma temporalidade única na qual interferem fatores complexos como o conjunto da cena, a subjetividade do artista e a participação do espectador. Além disso, a performance faz coincidir dois tempos fundamentais: 0 tempo da produção e o tempo em que é dado ao público. Assim, os momentos subjetivos da experiência do artista e dos espectadores acabam entrando em choque com o tempo cronológico do relógio, impedindo que o processo criativo se desenrole de maneira uniforme. E o jogo que se observa, apesar da dimensão conceitual do processo criativo da performance, é uma aposta em favor da imaginação e das impressões sensíveis, corporais, do espectador, mais do que de sua racionalização lógica:

As performances trabalham com todos os canais da percepção, isso se dando, tanto de forma alternada, quanto simultânea. Elas são 
construídas sobre experiências tácteis, motoras, acústicas, cinestésicas e, particularmente, visuais. (GLUSBERG, 2009, p.71)

Assim, cada espetáculo é único. E as sequências gestuais do performer, repetemse indefinidamente sempre em diferença, a cada representação. Nesse aspecto as performances podem ser consideradas como formas engendradas segundo a lógica fractal. As formas fractais, como veremos mais adiante, propiciam uma apreensão de relações e ritmos que seriam, na realidade, impensáveis e intraduzíveis para uma lógica linear e totalizadora, porque configuram formas infinitamente progressivas, desdobráveis e imperfeitas.

A cena performática constitui um espaço que se desdobra a partir da mobilidade de códigos e imagens que deixam vislumbrar a dimensão fracionária do mundo. $\mathrm{Na}$ performance, é impossível uma totalização ontológica. Diante de sua geometria subdivisível e aglutinadora, sempre haverá uma distância a mais para transpor, sempre um outro caminho a seguir:

\begin{abstract}
Desse modo o performer cria sobre a arena da performance uma clara consciência de seus atos imprevistos e de seus fracassos. Porque o discurso do performer está cheio de buracos e fissuras. Como o caminho a que alude o célebre poema de Antônio Machado, a performance se elabora ao desenvolver-se. (GLUSBERG, 2009, p. 84)
\end{abstract}

Em outro aspecto, os movimentos do corpo no espaço/tempo semiotizado no momento da performance não se vinculam a um objetivo utilitário, mas visam à experiência de sondar a matéria do mundo, as texturas que o constituem. O corpo testa sua própria presença e tateia o saber que emana das sensações provocadas pela experiência motora vivenciada como um fim em si mesmo. Nessa perspectiva, a experiência do corpo na ação performática também gera uma temporalidade semelhante ao que se constitui na experiência mística do ritual. O espetáculo força a abertura de um tempo/espaço "fora da experiência comum", engendrando um momento descontínuo em que a criação tem seu curso pautado também no improviso e no acaso do encontro entre o corpo em movimento e os objetos presentes no espaço público. 
Como nos rituais, a palavra, quando é pronunciada, também não visa a expressar apenas ideias e pensamentos dados: o performer usa o texto mais como significante do que como significado. Tendo a repetição como elemento constitutivo, os textos (re)citados geram um efeito hipnótico, o chamado efeito zen. E esse efeito pode engendrar um processo cognitivo que vai além da dimensão referencial e semântica da palavra, revelando a exterioridade da dimensão convencional do signo verbal propriamente dito. Nesse contexto a palavra pode ser usada por seu ritmo, extensão e textura, compondo a dimensão sonora da cena. Ela usada como um artifício de mise-en-scène, da mesma maneira que as cores e a luz etc.

Outro aspecto importante da ação performática é uma prática, bastante comum, de deformar a voz do artista por meios eletrônicos. Esse artifício, além de trazer à cena elementos do cotidiano moderno/urbano, sublinha o caráter de representação do espetáculo, despersonalizando a figura humana. Nesse caso, a voz reproduzida por meio eletrônico funciona como uma máscara ritual, fazendo personar uma voz estilizada, que não é totalmente humana nem compõe a imagem de um personagem:

$\mathrm{Na}$ performance geralmente se trabalha com persona e não personagens. A persona diz respeito a algo mais universal, arquetípico (ex: o velho, o jovem, o urso, o diabo, a morte etc). A personagem é mais referencial. Uma persona é uma galeria de personagens.

(COHEN, 2009, p. 107)

A partir dessas reflexões é possível pensar o conceito de performance como uma dinâmica de criação na/da linguagem poético-ritual. Como nos rituais, a performance configura imagens que se constituem e se dissolvem sem um compromisso com a expressão fiel do pensamento ou com um mundo referencial. Como na poesia, palavra posta em cena, visa a uma eficácia rítmica e imagética, evidenciando o saber do corpo que as pronuncia e de sua dimensão sensível, sua corporeidade. O corpo é, assim, portador de um saber que se expressa não apenas como pensamento, mas também no verso e no reverso de posturas comportamentais muitas vezes silenciosas. 
Amplia-se assim o conceito de corpo [...]. Este é compreendido neste contexto não apenas como espaço físico, mas já como entidade comunicativa, como trânsito e movimento, como mídia e pensamento, como história e narrativa. Estamos, portanto, diante de um corpo semiótico e cultural, composto de significados, símbolos e sinais, de memória e de histórias, tanto quanto de órgãos e trocas bioquímicas. (BAITELLO JUNIOR, 2006, p.85)

Não cabe, aqui, uma discussão detalhada a respeito das várias manifestações estéticas da chamada performance artística. Basta observar que ela apresenta, como característica geral, um projeto que pode envolver a linguagem das artes cênicas, das artes plásticas, da música e da poesia. A performance atua por meio de intervenções em espaços públicos ou abertos, atraindo, em muitos casos, o espectador para a cena artística. Além disso, ela costuma acontecer em espetáculos sem um texto fechado, abrindo espaço para o improviso e para a contingência de cada realização. Em síntese, a performance constitui-se como elemento de transposição, um salto entre o espaço público e o privado, entre o individual e o coletivo, entre a cena teatral e o cotidiano, questionando valores instituídos e práticas sociais codificadas.

Ressalte-se a importância de se refletir a respeito da performance no campo da poesia como um ato público de intervenção questionadora de valores estéticos e éticos. Assim, tendo como ponto de partida as discussões expostas acima, analisaremos, em seguida, o poema Korso, do escritor português Luis Serguilha, usando o conceito de performance como operador de leitura.

A escolha dessa obra se deve à maneira como ela se organiza, constituindo momentos de transposição de fronteiras importantes na organização social do espaço público e privado. Esse poema foi publicado pela editora brasileira Dulcinéia Catadora em volumes impressos em papel reciclado. Cada volume dessa obra é original, com capas trazendo imagens pintadas a mão, mantendo, porém, elementos próprios às embalagens industriais: papelão recortado de caixas, com avisos sobre o material embalado e a posição correta para o transporte. Nesse aspecto os livros, enquanto objetos artísticos, explicitam a 
intercomunicação muitas vezes invisível entre o espaço da produção da obra artístico-literária, de um lado, e o espaço do mercado e da indústria de outro.

Além disso, expondo os resíduos de embalagem de objetos de consumo cotidiano nas capas que envolvem o texto poético, os livros denunciam a dimensão convencional do valor atribuído à poesia, ao mesmo tempo em que chamam à cena poética as experiências usuais da sociedade atual e os códigos inerentes a eles. A performance, nesse contexto, embaralha as fronteira dos valores culturais socialmente constituídos e revelam novas possibilidades de experiência artística, para além da estética convencional.

O projeto editorial é um trabalho elaborado artesanalmente por filhos de catadores de papel, o que faz confundir o lugar de criação coletiva de artistas anônimos e o do autor propriamente dito. Pode-se dizer então que, no gesto único de pintar imagens diretamente sobre o papelão cru que compõe as capas de cada livro, os artesãos colocam em cena o saber de um corpo coletivo e individual a um só tempo. E esse saber se deixa ver, clandestinamente, por entre os gestos realizados no espaço performático que ele mesmo constitui, denunciando os "programas" socialmente construídos pela cultura hegemônica.

Cada livro é um objeto único, mas as suas condições de produção, o projeto conceitual que rege o processo de elaboração do conjunto dos livros é fixo. Do mesmo modo, o processo de criação dos poemas em Korso guia-se por estruturas que se repetem em diferença a partir de uma lógica não-linear, à maneira de um algorítimo: repetições formulares e sequenciais que tendem ao infinito. Sobre Korso, o poeta-crítico Melo e Castro(2005) afirma: "trata-se obviamente (...) de algorítimos liguísticos sequenciais cujo fim depende apenas de quem os pratica" (MELO E CASTRO, 2005, p.19)

Observe-se que os poemas de Sergilha, da mesma maneira que o processo de elaboração dos livros na editora Dulcinéia Catadora, seguem essa mesma lógica que joga com a potencialidade infinita do gesto criador em sua dimensão performática:

Texto Digital, Florianópolis, v. 10, n. 1, p. 174-186, jan./jul. 2014. ISSNe: 1807-9288 


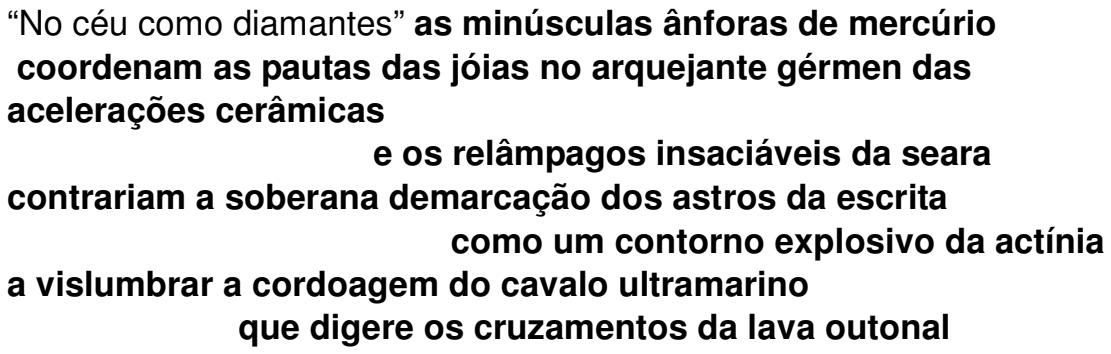

(SERGUILHA, 2009.p.5)

Observe-se que os versos de Korso configuram cadeias de orações dispostas, predominantemente, em uma relação de subordinação. E esses blocos imagéticos não sustentam campos semânticos estáveis: as palavras que compõem as imagens são postas em rota de colisão e geram sentidos paradoxais. As palavras se reúnem em configurações que não descartam as substituições aleatórias no eixo paradigmático e o processo de sequenciação nãolinear.

O título do poema de Serguilha, Korso, refere-se a uma dança tribal do Quênia, dança de improvisação coletiva que, no texto, é transfigurada em palavras que arrastam sentidos em linhas quebradas, estendendo-se indefinidamente. E a poesia de Luis Serguilha constitui um exemplo interessante de criação de uma cosmogonia, CORPO/GAIA, que atravessa escalas, seguindo uma geometria fractal:

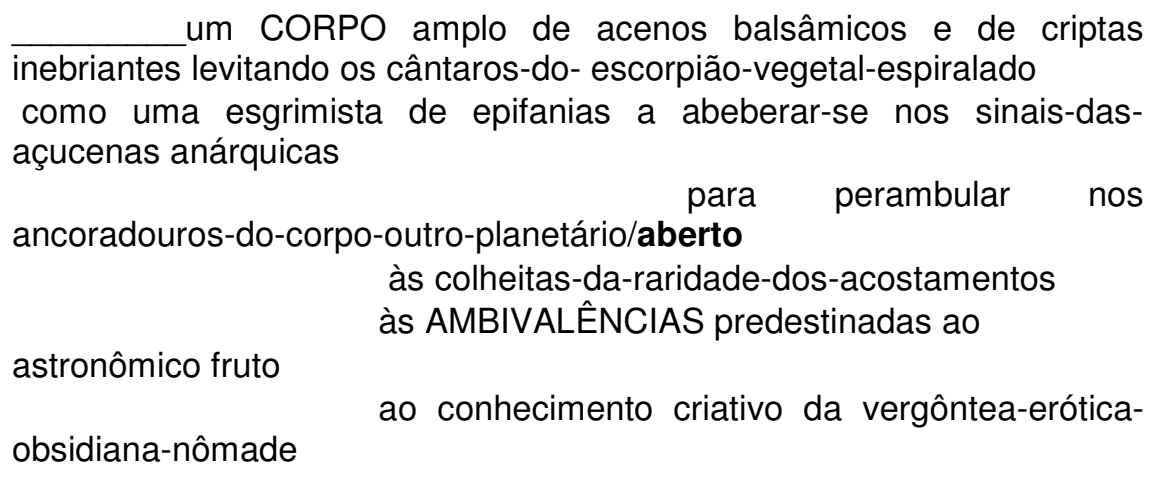
: GAIA: 
Nessa obra, o magma resultante de imagens em estado de fluxo potencializa a força geradora de formas e sentidos. A justaposição paradoxal de palavras de campos semânticos distantes faz surgir um cosmos que não se limita a uma organização ontológica estável.

Ora, sabemos que, nas tradições míticas, o homem organiza o cosmos para humanizá-lo, tornando-o, assim, habitável. Na verdade, pode-se dizer que as construções míticas de mundo representam um mapeamento cognitivo capaz de guiar a ação humana no mundo e gerar hierarquias, gerenciando a história e os papéis sociais. Compreender, nesse caso, seria circunscrever o universo dentro dos limites do humano.

Os poemas de Korso, no entanto, trazem ao cosmos formas fractais que se movem de maneira instável negando-se a constituir um espaço habitável. Como já foi dito, trata-se de um texto recitado por palavras forçadas a repetir infinitamente uma mesma relação combinatória em um eixo paradigmático aberto:

[...] devemos ter em conta que o discurso do corpo se forma a partir de sucessivas seleções do paradigma, seleções que produzem o sintagma. Contudo, enquanto nos demais processos de comunicação a seleção se realiza de acordo com número finito, fechado, nas performances não existe tal fechamento: o paradigma é aberto. (GLUSBERG, 2009, p.77)

De maneira similar, no campo da matemática alguns estudiosos dos fractais criaram abstrações interessantes que apresentam formas infinitas absurdamente contidas em espaços finitos, a partir de um procedimento de repetição em diferença. Cada objeto desses representa uma equação ${ }^{2}$ que, em lugar de levar a uma solução final, reduplica o problema, evitando sempre uma resposta.

A geometria padrão toma uma equação e pede o conjunto de números que a satisfazem (...). Mas, quando um geômetra repete uma equação em lugar de resolvê-la, a equação se torna um processo em lugar de uma descrição, dinâmica em lugar de estática. (GLEICK, 1990, p.219)

\footnotetext{
${ }^{2}$ No caso do conjunto de Mandelbrot, a equação é a seguinte:

$\mathbf{z} \rightarrow \mathbf{z}^{2}+\mathbf{c}$. "Tome-se um número, multiplique-se esse número por ele mesmo, e acrescente-se o número original." Cf. GLEICK, 1990, p. 220.
} 
A geometria fractal busca representar as formas infinitas que se dobram, quebram ou se ramificam. Ou seja, busca representar as formas dos objetos e o movimento dos fenômenos em uma complexidade que se assemelha à natural. De fato, são vários os exemplos, na natureza e no organismo humano, de formas que se autorepetem (sempre em diferença), criando dobraduras ou trilhas que se ramificam à maneira de labirintos, atravessando escalas: "As nuvens não são esferas (...). As montanhas não são cones. O relâmpago não percorre uma linha reta. (...). É a geometria das reentrâncias, depressões, do que é fragmentado, torcido, emaranhado e entrelaçado" (GLEICK,1990, p.90).

Semelhantemente, os versos de Serguilha, em seu percurso performático, parecem constituir um movimento cuja inércia pode levar o texto a fluir de maneira quase autônoma, como uma cascata, um rio ou a chuva. Mas essa força inercial não revela um inconsciente (subjetivo), mas a exterioridade de um mundo estranhamente codificado. Após ter sido posto em processo, o texto se desdobra em moto-contínuo, como uma equação não-linear, parecendo querer engolir a totalidade das palavras. Como afirma Melo e Castro: "[...] e se o máximo de palavras for o inesgotável repertório de um língua, tendendo assintóticamente para o infinito?" (MELO E CASTRO, 2004, p.8).

E o sujeito poético, paradoxalmente distanciado de sua dimensão subjetiva, recita as formas esquemáticas, relata um fluxo de imagens postas em delírio, gerando uma paisagem sonora feita de estranhamentos.

Efetivamente uma das impressões mais fortes que se recolhe da leitura da poesia de Serguilha é a sua matriz oral, de discurso que não tem fim e que se alimenta da própria música das palavras, adaptando-se mal às limitações do formato da página em branco dos livros. Assim pode-se perguntar qual a função da respiração na escrita e na leitura destes poemas: se é ela que determina o espaço que eles habitam e lhes é próprio. A voz poética parece (per)sonar, através de uma máscara ritual, um fluxo de palavras que marcam ritmos instáveis, em um movimento hipnótica e desconcertante. Constitui-se, assim, um espaço 
performático que evidencia o corpo semiótico das palavras, pondo em cena o ritmo de uma dança sequer coreografada.

Assim, nos poemas que compõem a obra Korso, vemos um cosmos construído a partir de um processo de radical despersonalização: sua estrutura projeta-se a partir de um esquema rítmico formular que se repete em diferença, infinitamente. O texto, dessa forma, acaba reduplicando e evidenciando a dimensão aleatória e contingencial do próprio mundo humano. E o jogo que se observa é uma aposta em favor das impressões sinestésicas do leitor, mais do que de sua compreensão lógica.

Korso faz um jogo intertextual com as poetas brasileiras Ana Maria Romero ${ }^{3}$ e Luci Collin ${ }^{4}$. Os poemas dessas autoras também são desdobrados e fragmentados até participarem da dimensão fractal da escrita de Serguilha. É interessante notar que, o processo de despersonalização do sujeito poético, apontado acima, acaba contribuindo para potencializar o erotismo presente na abra:

GAIA-DESEJO-ANA:

corpo redescoberto nos ecos unidos-arrebatadores das

Palavras GAIA-montanha de reverberações-jaguar-condor

na mediterrânica claridade das interferências de outro corpo-leitor:

intraduzível-corsário onde a obscuridade-ardente

ilimita-se no soalho da

identidade-do-desejo-livre

(SERGUILHA, 2009, p.24)

Nos versos de Serguilha, títulos e trechos dos poemas das autoras brasileiras são remodulados, constituindo-se como "atratores estranhos" "que não estabilizam os

\footnotetext{
${ }^{3}$ Cf. <http://www.gargantadaserpente.com/toca/poetas/ana ramiro.php>. Acesso em: 07 jul. 2011.

${ }^{4}$ Cf. http://www.cronopios.com.br/site/prosa.asp?id=3645>. Acesso em: 07 jul. 2011.

5 Expressão usada, no campo da termodinâmica, para designar a curva que se refere, graficamente, ao comportamento orbital dos sistemas complexos, ou fluxos turbulentos.
} 
poemas, mas aceleram o seu movimento rumo ao deslimite. E as imagens que surgem desse jogo erótico/tradutório assumem a mesma força telúrica que move todas as palavras pronunciadas nos poemas e todas as outras possíveis em uma dança com o infinito.

Em síntese, pode-se dizer que a obra analisada constitui uma dimensão performática que integra a experiência de um espaço descontínuo e revela a exterioridade dos códigos compartilhados. Nesse espaço estrangeiro, o leitor é convidado a participar de um espetáculo que se abre ao coletivo. E o texto também envolve o leitor nessa festa dionisíaca sem início ou fim. Os poemas, assim, afirmam o movimento erótico da relação constituída como saber que surge a partir do corpo que é ritmo, canto, dança, mas que também é (des)mundo.

\section{“PERFORMANCE”: THE MOBILITY PUT IN SCENE}

ABSTRACT: We will focus, in this article, the work of the Portuguese writer Luis Korso Serguilha which was published by the Brazilian publisher Dulcinea Catadora in printed volumes on recycled paper and edited by collectors of paper's children. For this analysis, we will use the concept of performance as reading operator.

KEYWORDS: Poetry. Dancing. Body. Performance.

\section{REFERÊNCIAS}

ANTÔNIO, Jorge Luiz. Os Hangares da poesia. In: SERGUILHA, Luís. Hangares do vendaval. Evora: Intensidez, 2007.

BAITELLO JUNIOR, Norval. O Corpo fora do corpo: a liberdade dos sonhos e símbolos. In: MOMMENSOHN, Maria (Org). Reflexões sobre Laban, o mestre dos movimentos. São Paulo: Summus, 2006.

CAMPBELL, Joseph. As transformações dos mitos através do tempo. São Paulo: Cultrix, 1997.

COHEN, Renato. Performance como linguagem. São Paulo Perspectiva, 2009.

GLEICK, Jemas. Caos. A criação de uma nova ciência. Trad. Waltenair Dutra. Rio de Janeiro: Campus, 1990.

GOLDBERG, Roselee. A arte da performance. Do Futurismo ao presente. Trad. Jefferson Luiz Camargo. São Paulo: Martins Fontes, 2006. 
GUISBURG, J; COELHO NETO; J. Teixeira; CHAVES CARDOSO, Reni. Semiologia do teatro. São Paulo Perspectiva, 1988.

ICLE, Gilberto. O ator como xamã. São Paulo: Perspectiva, 2006.

MELO E CASTRO, E. M. Prefácio. In: SERGUILHA, Luís. Embarcações. Lisboa: Ed. Ausência, 2004.

Prefácio. In: SERGUILHA, Luís. Singradura do Capinador. Lisboa: Ed. Indícios de oiro, 2005.

MOMMENSOHN, Maria, PETRELLA, Paulo (Orgs). Reflexões sobre Laban, o mestre do movimento. São Paulo: Summus, 2006. p.85.

SERGUILHA, Luís. Korso. Rio de Janeiro: Dulcinéia Catadora, 2009.

VIVEIRO DE CASTRO, Eduardo. Notas sobre a Cosmologia Yawalapiti. Religião e Sociedade. Rio de Janeiro: 3: 163-174.

ZUMTHOR, Paul. Performance, recepção, leitura. Trad. Jerusa Pires Ferreira e Suely Fenerich. São Paulo: Cosac Naify, 2007.

Texto recebido em: 14/07/2014. 